Rapid Reviews COVID-19

\title{
Review 1: "Prisons and Pandemics"
}

\section{Lauren Lyons ${ }^{1}$}

${ }^{1}$ Rutgers University

Published on: Aug 20, 2020

DOI: $10.21428 / 2 \mathrm{e} 3983 \mathrm{f5} . \mathrm{c937} \mathrm{c700}$

License: Creative Commons Attribution 4.0 International License (CC-BY 4.0). 


\section{$\underline{\text { RR:C19 Evidence Scale rating by reviewer: }}$}

- Strong. The main study claims are very well-justified by the data and analytic methods used. There is little room for doubt that the study produced has very similar results and conclusions as compared with the hypothetical ideal study. The study's main claims should be considered conclusive and actionable without reservation.

$* * * * * * * * * * * * * * * * * * * * * * * * * * * * * * * * * * * * * * * *$

\section{Review:}

What an excellent paper! The discussion was broad but focused, clear, and engaging. I was especially impressed by the depth of the authors engagement with epidemiological, legal, and moral arguments- from what I have seen written on this topic, this is unprecedented. Though the paper does not include concrete policy proposals, it effectively identities the classes of costs and benefits relevant to the issues and identifies the key trade-offs and points of contention. I hope this article is published and read widely.

One general thought is that I wished the authors would have noted the potential longterm implications of the sort of early release policies: namely, that they may provide a blueprint for decarceration. This idea is especially relevant considering ongoing debates about decarceration and abolitionism amidst ongoing \#blacklivesmatter movements. If it is the case that we can release huge numbers of peoples from jails and prisons without any significant effects on public safety, we ought to rethink much of the basic structure of the criminal justice system as is.

Here are some more specific comments:

In section II, "The Response to the Coronavirus in U.S. Prisons," it would have been nice to hear a bit more about policy responses outside of the U.S. context. Indeed, the U.S. response has been especially egregious, and even more so when compared with other countries that have implemented more sweeping measures. Turkey and Afghanistan, for instance, have reduced their populations by over 30 percent. Maybe the authors think that these reductions are still insufficient.

I was interested in the authors' claim that "the fundamental problem is that incarcerated people have a moral and legal right to a safe environment while confined 
by U.S. law enforcement." Many would argue that carceral environments are rarely, if ever, safe. Is this moral/legal right violated in "normal" times? Or do conditions related to the pandemic cross an important threshold, where threats to one's safety are too grave?

I also wonder how the discussion of human right to health would apply to the case of other essential workers during the pandemic. For instance, should companies who run meat-processing facilities with high numbers of cases too be obligated to provide their employees with paid time off or other benefits because they must respect their human right to health?

It would be nice to hear about the Nelson Mandela Rules- perhaps regarding some instances where the rules were applied, and how those cases related to incarceration during the pandemic. I found this mention rather brief, especially considering the detail of the discussion about the human right to health in general.

I though one of the real strengths of the paper was the arguments about special obligations to people who are dependent on us for their welfare, the relevance of selfdefense, and duties to vulnerable people during the crisis. Great stuff!

I also really like the proviso that "the process of releasing individuals would not be arbitrary, discriminatory, or politically driven."

I do worry that many legal theorists would push back on your claim that "we cannot punish" people for crimes before they have been convicted; holding people who have been arrested is not supposed to be reprobative." It seems that the common view is that pretrial detention does not constitute punishment because it is not intentionally inflicted as punishment.

A final note is that hopefully, we should soon have a little more data about recidivism rates for those released on emergency release policies during the pandemic. I know there is a study in the sociology department at University of Washington, as well as some ongoing work in New York City. I believe sociologist Bruce Western has altered a longitudinal study he is doing on Rikers Island in order to gather more info about the efficacy of emergency release polices. There is some info on his website! 
